\title{
Should the Management Approach to the Anterior Abdominal Stab Wound be Different in Patients with Self-inflicted Abdominal Injury?
}

Yehuda Hershkovitz ( $\square$ yehuda_her@hotmail.com )

Yitzhak Shamir Medical Center https://orcid.org/0000-0002-8361-4555

Itamar Ashkenazy

Rambam Health Care Campus

Igor Kalman

Clalit Health Services

Kobi Peleg

Gertner Institute for Health Policy and Epidemiology

Moran Bodas

Gertner Institute for Health Policy and Epidemiology

Adi Givon

Gertner Institute for Health Policy and Epidemiology

Zahar Shapira

Yitzhak Shamir Medical Center

Igor Jeroukhimov

Yitzhak Shamir Medical Center

Research article

Keywords: penetrating abdominal trauma, self inflicted injury, laparotomy

Posted Date: July 20th, 2020

DOI: https://doi.org/10.21203/rs.3.rs-42237/v1

License: (c) (i) This work is licensed under a Creative Commons Attribution 4.0 International License. Read Full License

Version of Record: A version of this preprint was published at Injury on February 1st, 2021. See the published version at https://doi.org/10.1016/j.injury.2020.11.072. 


\section{Abstract}

\section{Background}

Self-inflicted injury is a leading cause of death worldwide. It is hypothesized that due to instincts for selfpreservation, the severity of abdominal injury would be decreased following suicidal self-stabbing in comparison to stab wounds from assault, and therefore a more conservative management might be considered.

\section{Methods}

All patients with isolated abdominal stab wound (SW) admitted to 19 Trauma Centers in Israel between the years 1997 and 2018 were included in the study. Patients with self-inflicted abdominal SW (Group I) were compared to victims with abdominal SW following assault (Group II).

Results

Group I included 9.4\% (314/3324) of patients eligible for this study. Compared to Group II, Group I patients were older (median: 39 years, IQR 28,52 vs. 24 years, IQR 19,33; $p<0.001$ ), had more females ( $28.7 \%$ vs $4.9 \%, p<0.001$ ), had longer length of hospitalization (median: 3 days vs. 2 days; $p<0.001$ ), underwent surgery more frequently $(55.4 \%$ vs. $37.4 \%$; $p<0.001)$, and had higher mortality $(2.9 \%$ vs. $0.7 \%$; $\mathrm{p}=0.002$ ). Possible covariates for mortality were examined and following logistic regression, self-inflicted injury remained associated with higher death rates compared to assault (OR 4.027, CI95\% 1.380, 11.749; $\mathrm{p}=0.011$ ).

Conclusion

In this study, patients with isolated self-inflicted abdominal injuries had higher mortality and more frequently underwent abdominal surgery.

\section{Background}

Anterior Abdominal stab wounds (AASW) are commonly encountered in trauma units. Suicide is a common cause of death worldwide [1]. However, suicide by self-stabbing is relatively rare and accounts for only $3 \%$ of suicide attempts [1]. Several studies showed lower injury severity scores (ISS) in selfinflicted injuries compared to victims of violence $[2,3]$. However, mortality rates were not lower. These studies also showed that patients with self-inflicted AASW underwent surgery more often and had a higher rate of non-therapeutic laparotomy (NTL). Theoretically, the lower ISS and the higher rate of NTL could be explained in part by the internal defensive instincts of self-preservation that the patient performing suicide might have at the time of inflicting self-injury.

Since the data on self-inflicted AASW is limited, this study sought to verify previous findings reported by others by using the data in the Israeli Trauma Registry. It was hypothesized that among the Israeli 
patients population, self-inflicted AASW would result in less serious injuries and probably less mortality.

\section{Material And Methods \\ Population and sample}

All patients older than 18 years of age with AASW who were admitted to 19 Israeli Trauma Centers between the years 1997 and 2018 were included in the study. The patients were divided in to 2 groups. Group I included patients with self-inflicted injury and group II - victims of assault. Patients with concomitant injuries classified as AIS $>2$ to non-abdominal organs were excluded from the study in order to rule out other causes that might affect the outcome.

\section{Data sources}

The data was retrospectively collected from the records of the Israeli National Trauma Registry (INTR) in the National Center for Trauma and Emergency Medicine Research at The Gertner Institute for Epidemiology and Health Policy Research. The INTR records data from all trauma patients with an ICD-9CM diagnosis code between 800 and 959.9, except for suffocations, drownings and poisoning, in almost all trauma centers in Israel. The INTR records all casualties hospitalized due to injury, those who died in the ED and those were transferred to another hospital. The INTR documents more than $90 \%$ of all trauma casualties and $98 \%$ of the severely injured trauma casualties in Israel. Excluded are casualties who died on scene or en route to hospital. Data is recorded by trained trauma registrars supervised by the trauma director and the trauma coordinator. Electronic files are transferred to the Israel National Center for Trauma and Emergency Medicine Research for quality assurance, in addition to structured logical tests in the registry software

\section{Variables}

The data collected from the registry included age, sex, injury severity core (Injury Severity Score (ISS) and Abbreviated Injury Scale (AIS)), systolic blood pressure on admission and mortality. It also included information concerning operations. Patient with systolic blood pressure $<90 \mathrm{mmHg}$ were considered hemodynamically unstable.

\section{Statistical analysis}

Differences in proportions between Group I and Group II were analyzed with either Chi-square test of independence or Fisher exact test. Age and hospitalization Length of Stay (LOS) differences were analyzed with Mann-Whitney test. Similar tests were used for categorical and continuous variables when patients who died in Group I were compared to patients who died in Group II. The combined effect of variables that were significantly associated with mortality were investigated using logistic regression. Possible interactions were incorporated into the model. Results are presented as odds ratio and $95 \%$ confidence intervals $(95 \% \mathrm{Cl})$. Statistical analysis was performed using SAS statistical software Version 9.2 (SAS Institute Inc., Cary, NC). P-values of less than 0.05 were considered statistically significant. 
Numbers, percentages and interquartile ranges (IQR) were approximated to the nearest decimal. Odds Ratio (OR), P value and $95 \%$ confidence interval $(95 \% \mathrm{Cl})$ values to the nearest thousandth.

This study was performed without any grants or other type of funding. The authors have not conflict of interest to declare.

\section{Results}

Overall, 3,324 patients with AASW were included in the study. Of these, 314 (9.4\%) patients were included in the self-inflicted injury (Group I). Comparison of sex and age between the two groups is detailed in Table 1. Almost all the patients in Group II were males. Patients in Group II were also younger when compared to patients in Group I.

Table 1

- Demographics of studied group $(\mathrm{N}=3,324)$

\begin{tabular}{|llll|}
\hline & $\begin{array}{l}\text { Group I - Self-inflicted Injury } \\
(\mathbf{n}=\mathbf{3 1 4})\end{array}$ & $\begin{array}{l}\text { Group II - SW Victims of Assault } \\
(\mathbf{n = 3 , 0 1 0 )}\end{array}$ & P value \\
\hline Gender & & & $<0.001$ \\
\hline Male & $224(71.3 \%)$ & $2864(95.2 \%)$ & \\
\hline Female & $90(28.7 \%)$ & $146(4.9 \%)$ & $<0.001$ \\
\hline Age, median years, IQR & $39(28,52)$ & $24(19,33)$ & \\
\hline SW = Stab Wound & & & \\
\hline
\end{tabular}

Table 2 describes the clinical presentation, ISS, incidence of intra-abdominal organs injury, and mortality across studied groups. There were no differences in frequency of the abdominal wall penetration and the frequency of internal organs injuries. When specific organs were evaluated, the rate of kidney injuries was higher in Group II patients. 
Table 2

- Outcomes of injury per study group $(\mathrm{N}=3,324)$

\begin{tabular}{|c|c|c|c|}
\hline Outcome & $\begin{array}{l}\text { Group I -SW Self-inflicted } \\
\text { Injury } \\
(n=314)\end{array}$ & $\begin{array}{l}\text { Group II - SW Victims of } \\
\text { Assault } \\
(n=3,010)\end{array}$ & $\begin{array}{l}\mathrm{P} \\
\text { value }\end{array}$ \\
\hline \multicolumn{4}{|l|}{ Abdominal Injury } \\
\hline No penetration & $102(32.5 \%)$ & $989(32.9 \%)$ & \multirow[t]{3}{*}{0.9} \\
\hline $\begin{array}{l}\text { Penetration with no } \\
\text { injury }\end{array}$ & $98(31.2 \%)$ & $962(32.0 \%)$ & \\
\hline Penetration with injury & $114(36.3 \%)$ & 1059 (35.2\%) & \\
\hline ISS $\geq 16$ & $24(7.6 \%)$ & $227(7.5 \%)$ & 0.948 \\
\hline Systolic BP $<90$ & $18(5.7 \%)$ & $205(6.8 \%)$ & 0.467 \\
\hline Abdominal surgery & $174(55.4 \%)$ & $1125(37.4 \%)$ & $\begin{array}{l}< \\
0.001\end{array}$ \\
\hline \multicolumn{4}{|l|}{ Organ injured } \\
\hline Great vessels & $17(5.4 \%)$ & $112(3.7 \%)$ & 0.185 \\
\hline Liver & $29(9.2 \%)$ & $267(8.9 \%)$ & 0.911 \\
\hline Kidney & $1(0.3 \%)$ & $116(3.9 \%)$ & 0.002 \\
\hline Spleen & $2(0.6 \%)$ & $73(2.4 \%)$ & 0.067 \\
\hline Stomach & $16(5.1 \%)$ & $117(3.9 \%)$ & 0.374 \\
\hline Pancreas & $3(1.0 \%)$ & $32(1.1 \%)$ & 0.859 \\
\hline Small Bowel & $31(9.9 \%)$ & $279(9.3 \%)$ & 0.804 \\
\hline Large Bowel & $13(4.1 \%)$ & $167(5.5 \%)$ & 0.359 \\
\hline LOS, median days (IQR) & $3(1,5)$ & $2(1,5)$ & $\begin{array}{l}< \\
0.001\end{array}$ \\
\hline Mortality & $9(2.7 \%)$ & $22(0.7 \%)$ & 0.002 \\
\hline
\end{tabular}

Though no differences in injury severity and frequency of internal injury were noted between the groups, more patients in Group I underwent abdominal surgery. Mortality was higher in Group I patients compared to Group II $(2.9 \%$ vs. $0.7 \%$, respectively; $p=0.002)$.

In order to evaluate whether self-inflicted injuries are an independent risk factor for mortality, other possible risk factors for mortality were evaluated (Table 3 ). The analysis shows that patients who died 
were older. Age, ISS, and hypotension on presentation were all significantly associated with mortality and thus could be considered as covariates.

Table 3

- Risk factors for mortality due to abdominal stab wounds $(\mathrm{N}=3,324)$

\begin{tabular}{|c|c|c|c|}
\hline & $\begin{array}{l}\text { Died } \\
\mathrm{N}=\mathbf{3 1}\end{array}$ & $\begin{array}{l}\text { Survived } \\
N=3293\end{array}$ & $P$ value \\
\hline \multicolumn{4}{|l|}{ Sex } \\
\hline Males & $30(96.8 \%)$ & $3058(92.9 \%)$ & \multirow[t]{2}{*}{0.722} \\
\hline Females & $1(3.2)$ & $235(7.1 \%)$ & \\
\hline Age, median years, (IQR) & $35(23,57)$ & $25(19,35)$ & 0.003 \\
\hline \multicolumn{4}{|l|}{ Abdominal Injury } \\
\hline No penetration & $3(9.7 \%)$ & $1088(33.0 \%)$ & \multirow[t]{3}{*}{$<0.001$} \\
\hline Penetration with no injury & $3(9.7 \%)$ & $1057(32.1 \%)$ & \\
\hline Penetration with injury & $25(80.6 \%)$ & 1148 (34.9\%) & \\
\hline$I S S \geq 16$ & $19(61.3)$ & $232(7.0)$ & $<0.001$ \\
\hline Systolic BP $<90$ & $19(61.3)$ & $204(6.2)$ & $<0.001$ \\
\hline Abdominal surgery & $24(77.4 \%)$ & $1275(38.7 \%)$ & $<0.001$ \\
\hline \multicolumn{4}{|l|}{ Injury Mechanism } \\
\hline Self-inflicted & $9(29.0 \%)$ & 305 (9.3\%) & \multirow[t]{2}{*}{0.002} \\
\hline Assault & $22(71.0 \%)$ & 2988 (90.7\%) & \\
\hline
\end{tabular}

The combined effect of these variables was investigated using logistic regression (Table 4). When the four significant covariates were analyzed together, all four remained significant, including self-inflicted injury. Possible interaction effects between the four covariates were all non-significant. 
Table 4

- Outcomes of logistic regression analysis of possible covariates of mortality due to stab wounds

\begin{tabular}{|llll|}
\hline Variable & Odds ratio & 95\% confidence interval & P value \\
\hline Age & 1.037 & $1.012,1.064$ & 0.004 \\
\hline Systolic BP $<90$ & 17.175 & $7.547,39.085$ & $<0.001$ \\
\hline ISS $\geq 16$ & 10.537 & $3.875,28.653$ & $<0.001$ \\
\hline Self-inflicted injury & 4.027 & $1.380,11.749$ & 0.011 \\
\hline ISS = Injury Severity Score; BP = Blood Pressure & \\
\hline
\end{tabular}

\section{Discussion}

Anterior Abdominal stab wounds (AASW) is a common cause for admission to surgical Emergency Rooms. Only $28 \%$ of patients suffering from AASW will end up having internal abdominal injury $[4,5]$. Still, due to limitations in arriving to a correct diagnosis, as many as $40-45.8 \%$ of said patients will undergo laparotomy. Clear indications for explorative laparotomy in an AASW patient include hemodynamic instability, peritonitis, evisceration, blood in the nasogastric tube, and/or on rectal examination $[1,6]$. Since only about a third of the patients with AASW require surgical exploration, further evaluation is warranted. Management approaches may include local wound exploration, computed tomography, diagnostic laparoscopy, or close clinical observation [7-10].

In this study, patients with self-inflicted AASW had a similar frequency of intra-abdominal injury, as well as similar frequency of high ISS compared to stab wound (SW) patients from an assault. Nevertheless, patients in Group I underwent surgery more frequently and they also had a higher mortality. Relatively similar results were presented by Matsomoto et al [2] who compared self-inflicted injuries to those presented due to violence using the Japanese Trauma Data Bank. In their study, $76.4 \%$ of abdominal stab wounds were self-inflicted. The authors reported lower ISS with the same mortality rate in self-inflicted injuries compared to those caused by violence. This result suggests that the association of ISS and mortality may be different in patients with self-inflicted injuries compared to assault. Other reports indicate that patients with self-inflicted SW were more commonly operated and that these patients had higher rate of NTL $(2,11)$. Higher rate of NTL may explain the discrepancy in the number of operations, and it might explain the discrepancy in the mortality. The data registered in the INTR did not allow to evaluate the rate of NTL in this study. The reason for higher NTL observed in other studies is also unclear $(2,3,11)$.

In an effort to explain this outcome, we can propose several possible explanations that should be examined in future studies. First, according to the literature, $60-98 \%$ of trauma patients due to suicide attempts suffer from mental problems (10). Those disorders include mostly depression and bipolar affective disorders in the older patients and mental distress due to personality crisis in younger patients 
(12). In the current study, as is the case in other mentioned studies, the rate of surgical interventions among patients with self-inflicted abdominal SW was higher. Higher rate of surgeries, might be due to communication problems with patient with mental disorder.

Second, patients with self-inflicted abdominal SW have a lower pain threshold, which might have an effect on the way they present pain (13). Since one of the indications for laparotomy include signs of peritoneal irritation, presentation of hypersensitivity might affect the decision to operate those patients. Incidence of hemodynamically instability, another indication for laparotomy, was the same in both groups and accounts for only $5.7-6.8 \%$ of the cases (Table 2 ).

\section{Limitations}

This study has several limitations. Though based on data recorded in a very large trauma registry the data that may interpret the results of this study is lacking. We are unable to evaluate why more patients in Group I were operated and why more patients in this group died. We do know, however, that self-inflicted injuries to the abdomen results in similar ISS and a similar injury profile as much as individual abdominal organs are concerned. Future studies dealing with self-inflicted injuries to the abdomen should concentrate on the reasons leading to increased proportion of surgeries and increased mortality rates.

\section{Conclusion}

Patients with self-inflicted stab injury to the abdomen have a higher frequency of abdominal surgery and higher mortality compared to patients similarly injured by an assault. The hypothesis that basic instincts for self-preservation would lead to better outcome was refuted. Consequently, management approaches of such patients that are based solely on repeated clinical examination may not be appropriate for these patients.

\section{Abbreviations}

SW stab wound, AASW - Anterior Abdominal stab wounds, NTL - non-therapeutic laparotomy, ISS injury severity score, AIS - Abbreviated Injury Scale, INTR - Israeli National Trauma Registry, LOS-length of stay, $\mathrm{Cl}$ - confidence intervals, IQR - interquartile ranges, OR - Odds Ratio,

\section{Declarations}

Ethics approval: This study was approved by the Ethical Committee of the Sheba Medical Center (approval number SMC-18-5138).

Consent for Publication: Not applicable.

Funding: no funding was provided. 
Availability of data and materials: The datasets analysed during the current study are not publicly available but are available from the corresponding author on reasonable request.

Competing interests: The authors declare that they have no competing interests.

Authors' contributions: Hershkowitz Y, Jeroukhimov I, Ashkenazy I - Conception, design of the work, interpretation of data, drafted the work. Peleg K, Givon A - the acquisition, analysis and interpretation of data. Bodas M, Shapira Z, Kalman I - substantively revised the work

Acknowledgement: Not applicable.

\section{References}

1. Plackett TP, Fleurat J, Putty B, Demetriades D, Plurad D. Selective nonoperative management of anterior abdominal stab wounds: 1992-2008. J Trauma. 2011 Feb;70(2):408-13.

2. Biffl WL, Kaups KL, Pham TN, Rowell SE, Jurkovich GJ, Burlew CC, Elterman J, Moore EE. Validating the Western Trauma Association algorithm for managing patients with anterior abdominal stab wounds: a Western Trauma Association multicenter trial. J Trauma. 2011 Dec;71(6):1494-502.

3. Abdullah F, Nuernberg A, Rabinovici R. Self-inflicted abdominal stab wounds. Injury. 2003 Jan;34(1):35-9.

4. Bukur M, Inaba K, Barmparas G, DuBose JJ, Lam L, Branco BC, Lustenberger T, Demetriades D. Selfinflicted penetrating injuries at a Level I Trauma Center. Injury. 2011 May;42(5):474-7.

5. Martin MJ, Brown CVR, Shatz DV, Alam HB, Brasel KJ, Hauser CJ, et al. Evaluation and management of abdominal stab wounds: A Western Trauma Association critical decisions algorithm. J Trauma Acute Care Surg. 2018 Nov;85(5):1007-15.

6. Dayananda K, Kong VY, Bruce JL, Oosthuizen GV, Laing GL, Clarke DL. Selective non-operative management of abdominal stab wounds is a safe and cost effective strategy: A South African experience. Ann R Coll Surg Engl. 2017 Jul;99(6):490-6.

7. Sarici is, Kalayci MU. Is computed tomography tractography reliable in patients with anterior abdominal stab wounds? Am J Emerg Med. 2018 Aug;36(8):1405-9.

8. Rasouli N, Malakouti SK, Rezaeian M, Saberi SM, Nojomi M, De Leo D, Ramezani-Farani A. Risk Factors of Suicide Death Based on Psychological Autopsy Method; a Case-Control Study. Arch Acad Emerg Med. 2019 Sep 1;7(1):e50.

9. Matsumoto S, Hayashida K, Furugori S, Shimizu M, Sekine K, Kitano M. Impact of self-inflicted injury on nontherapeutic laparotomy in patients with abdominal stab wounds. Injury. 2018 Sep;49(9):1706-11.

10. Bugaev N, McKay K, Breeze JL, Arabian SS, Rabinovici R. Self-Inflicted Abdominal Stab Wounds Have a Higher Rate of Non-therapeutic Laparotomy/Laparoscopy and a Lower Risk of Injury. World J Surg. 2017 Nov;41(11):2681-8. 
11. Bachmann S. Epidemiology of Suicide and the Psychiatric Perspective. Int J Environ Res Public Health. 2018 Jul 6;15(7).

12. Michaelides $A$, Zis $P$. Depression, anxiety and acute pain: links and management challenges. Postgrad Med. 2019 Sep;131(7):438-44.

13. Banerjee A, Zhou HY, Kelly KB, Downs BD, Como JJ, Claridge JA. Anterior abdominal stab injury: a comparison of self-inflicted and intentional third-party stabbings. Am J Surg. 2013 Mar;205(3):2748. 